\title{
artigo
}

Alves, L.L.; Alves, L.L.; Oliveira, R.I.S.; Santos, L.X.C.; Melo, L.M.F.; Santos, S.S.R.; Santos Silva, M.; Dantas, M.M.

Avaliação de metais pesados e poluentes ambientais no Rio do Sal (Nossa Senhora do Socorro - SE) e seu impacto na saúde humana

\section{Avaliação de metais pesados e poluentes ambientais no Rio do Sal (Nossa Senhora do Socorro - SE) e seu impacto na saúde humana}

\author{
Evaluation of heavy metals and environmental pollutants in Rio do Sal (Nossa Senhora do Socorro - SE) and its impact \\ on human health \\ Evaluación de metales pesados y contaminantes ambientales en el Rio do Sal (Nossa Senhora do Socorro - SE) y su \\ impacto en la salud humana
}

\begin{abstract}
RESUMO
O objetivo deste artigo foi analisar metais pesados e poluentes no Rio do Sal e o seu impacto na saúde humana, considerando que moradores de suas margens o utiliza como fonte de alimento, água e lazer. Atualmente um dos problemas ambientais mais comuns é a poluição química decorrente dos despejos residenciais e industriais. Tendo em vista ao tempo que os metais pesados persistem em corpos hídricos, torna-se fundamental uma pesquisa acerca de seus níveis no meio ambiente. 0 método aplicado foi uma coleta de dados realizada em junho de 2011 as margens do Rio do Sal localizado em Nossa Senhora do Socorro/SE. A análise empregada foi através de Espectroscopia de Absorção Atômica. O resultado demonstrou a presença de metais pesados que ultrapassam o limite máximo permito pelo CONAMA. A conclusão revelou, portanto, que o Rio do Sal é considerado impróprio para consumo humano devido a quantidades elevadas de cobre.
\end{abstract}

DESCRITORES: Toxicologia; Análise Ambiental; Metais Pesados.

\begin{abstract}
The purpose of this article was to analyze the concentration levels of heavy metals and pollutants into the Rio do Sal as, given that residents of its banks have used it as food, water and leisure sources. One of the most common environmental problems is the chemical pollution resulting from residential and industrial effluents. Considering the period that heavy metals persist in water bodies, it is essential to evaluate their levels of incidence in the environment. The method applied was a data collection conducted in June 2011 in the banks of the studied river located in Nossa Senhora do Socorro/SE. For the analysis, atomic absorption spectroscopy was applied. The result demonstrated high concentration of heavy metals that exceed the maximum level allowed by CONAMA. The conclusion revealed, therefore, that Rio do Sal is unsuitable for human consumption due to elevated amounts of copper.
\end{abstract}

DESCRIPTORS: Toxicology; Environmental Analysis; Heavy Metals.

\section{RESUMEN}

El objetivo del artículo fue analizar metales pesados y contaminantes del Río de Sal y su impacto en la salud humana, considerando que residentes de sus márgenes lo utiliza como fuente de alimento, agua y entretenimiento. Actualmente uno problema ambiental común es la contaminación química derivada de los vertidos residenciales e industriales. En vista del tiempo que los metales pesados persisten en cuerpos hídricos, resulta fundamental investigar sus niveles en el medio ambiente. El método aplicado fue una colecta de datos realizada en junio de 2011 a orillas del Río de Sal ubicado en Nossa Senhora do Socorro/SE. El análisis empleado fue mediante una Espectroscopia de Absorción Atómica. El resultado mostró la presencia de metales pesados que superan el límite máximo permitido por el CONAMA. La conclusión reveló, entonces, que el Río de Sal no es considerado apto para el consumo humano debido a las elevadas cantidades de cobre.

DESCRIPTORES: Toxicología; Análisis Ambiental; Metales Pesados.

RECEBIDO EM: 16/11/2020 APROVADO EM: 15/12/2020 


\section{Lumar Lucena Alves}

Medical Technologist, Gerald Champion Regional Medical Center - GCRMC, NM, USA, Graduado em Biomedicina, Universidade Tiradentes, Aracaju, Brasil.

ORCID: 0000-0002-0375-1286

\section{Luan Lucena Alves}

Graduando em Ciências Biológicas, Universidade Paulista, São Paulo, Brasil.

ORCID: 0000-0003-2414-6840

\section{Raphaella Ingrid Santana Oliveira}

Professora no Centro Universitário Estácio de Sergipe, Graduada em Biomedicina, Mestre em Biotecnologia Industrial, Universidade Tiradentes, Aracaju, Brasil.

ORCID: 0000-0002-7027-9049

\section{Lorena Xavier Conceição Santos}

Professora no Centro Universitário Estácio de Sergipe, Graduada em Ciências Biológicas, Mestre em Saúde e Ambiente, Universidade Tiradentes, Doutora em Desenvolvimento e Meio Ambiente, Universidade Federal de Sergipe, Aracaju, Brasil.

ORCID: 0000-0001-5995-2442

\section{Larissa Maria Freire de Melo}

Graduanda em Biomedicina, Centro Universitário Estácio de Sergipe, Aracaju, Brasil.

ORCID: 0000-0003-2803-0845

\section{Stephanie Sophia Rodrigues dos Santos}

Graduanda em Biomedicina, Centro Universitário Estácio de Sergipe, Aracaju, Brasil.

ORCID: 0000-0003-2490-1965

\section{Miryan Santos Silva}

Graduanda em Enfermagem, Centro Universitário Estácio de Sergipe, Aracaju, Brasil.

ORCID: 0000-0003-2612-3626

\section{Mylena Martins Dantas}

Graduada em Biomedicina, Universidade Tiradentes, Graduanda em Enfermagem, Centro Universitário Estácio de Sergipe, Aracaju, Brasil.

ORCID: 0000-0002-6843-7968

\section{INTRODUÇÃO}

$\mathbf{U}$ $\mathrm{m}$ dos problemas mais sérios que afetam o meio ambiente é a poluição química de natureza orgânica ou inorgânica, que ocorre devido aos despejos residenciais e industriais. Define-se como poluição qualquer alteração física, química ou biológica que cause modificação no ciclo biológico normal, interferindo na fauna e flora do meio. A poluição aquática, uma das mais sérias, provoca mudanças nas características físicas, químicas e biológicas das águas, as quais são determinantes para a sua qualidade, podendo impossibilitar o seu uso para o consumo humano ${ }^{1}$.

O crescente aumento do descarte de metais pesados no meio ambiente, ou mesmo o seu uso indevido na agricultura, através de atividades industriais e de mineração, dentre outras, causam um significativo problema ambiental com riscos muitas vezes desconhecidos ${ }^{2}$. Quimicamente, os metais pesados são definidos como um grupo de elementos situados entre o Cobre e o Chumbo na tabela periódica tendo pesos atômicos entre 63,546 e 200,590 e densidade superior a $4,0 \mathrm{~g} / \mathrm{cm}^{33}$. Porém, a toxicidade ocorrerá quando suas concentrações excederem o limite de tolerância dos organismos, ou seja, dentro de certos parâmetros não causarão problemas aos seres vivos ${ }^{3}$.

Alguns destes metais pesados estão entre os mais danosos poluentes. São conhecidos como metais tóxicos, sendo os principais o chumbo, o cádmio e o mercúrio. $\mathrm{O}$ mecanismo de toxicidade mais relevante é certamente a inativação de en- zimas $^{4}$. Isto ocorre com metal de transição bivalente reagindo com os grupos amino e sulfidrilas das proteínas. Alguns deles podem competir com elementos essenciais e substituí-los no metabolismo enzimático, como o zinco, o cobre, o mercúrio, o ferro, entre outros, por exemplo. Alguns metais podem ainda danificar células, por agirem como anti-metabólicos ou por formarem precipitados ou quelatos com agentes metabólicos essenciais ${ }^{5,6}$.

O Rio do Sal é uma sub-bacia do Rio Sergipe e é o principal abastecedor hidrográfico do município de Nossa Senhora do Socorro além de também fornecer água para Aracaju ${ }^{7}$ É um rio que possui extensão de $20,5 \mathrm{~km}$ drenando uma área de aproximadamente $62 \mathrm{~km}^{2}$. No entanto, nos dias atuais, este afluente vem sofrendo 


\section{artigo}

Alves, L.L.; Alves, L.L.; Oliveira, R.I.S.; Santos, L.X.C.; Melo, L.M.F.; Santos, S.S.R.; Santos Silva, M.; Dantas, M.M.

Avaliação de metais pesados e poluentes ambientais no Rio do Sal (Nossa Senhora do Socorro - SE) e seu impacto na saúde humana

forte degradação ecológica devido à ação do homem. Desmatamento para a construção de prédios, construção de palafitas na região, lançamento de efluentes industriais e domésticos são apenas algumas das principais ações antrópicas que vem agredindo o meio ambiente local ${ }^{8}$. Localizado no Norte do estado, o Rio do Sal contribui para o abastecimento de água das áreas menos prevalecidas de Aracaju e Nossa Senhora do Socorro, a exemplo do Lamarão, Bugio, Soledade e Porto Dantas?.

O Rio do Sal leva este nome devido à grande exploração de salinas que ocorria na década de 80 , porém essa exploração hoje não tem tantos lucros como antigamente. Apesar disso, este afluente ainda é bastante utilizado pela população local para o desenvolvimento da atividade econômica da região através de sua alta funcionalidade, tais como pesca, uso da argila, abastecimento doméstico e irrigação. Contudo, a falta da prática de sustentabilidade ambiental vem afetando consideravelmente o ambiente ecológico, atingindo diretamente a população que faz do Rio do Sal benefício próprio ${ }^{10}$.

Tendo em vista o alto tempo de persistência dos metais pesados em corpos hídricos, é fundamental que a avaliação dos seus níveis de contaminação possa transcender as diagnoses baseadas unicamente na comparação com os índices legais, e incorporem uma análise dinâmica das concentrações monitoradas, através de estudos que permitam entender o comportamento no meio aquoso e forneçam bases mais sólidas para a avaliação do risco a eles associado ${ }^{5}$. Portanto, este estudo objetivou a análise de metais pesados no Rio do Sal, bem como a presença de poluentes que possam interferir na qualidade da água considerando que moradores de suas margens utilizam-o como fonte de alimento, água e lazer, os quais podem estar consumindo uma água contaminada por metais pesados e diversos poluentes que podem trazer problemas de saúde futuros.

\section{MÉTODOS}

Constou de um estudo bibliográfico e in loco a fim de analisar as amostras de água do Rio do Sal. A coleta de dados foi realizada no dia 12 de junho de 2011 às margens do Rio do Sal localizado no Conjunto Governador João Alves Filho - Nossa Senhora do Socorro/ SE. A coleta foi realizada no período da manhã às 9:00 e foram utilizados recipientes plásticos estéreis de boca larga para a coleta de $500 \mathrm{~mL}$ de água para avaliação. As condições ambientais estavam favoráveis e não havia chovido nos últimos sete dias. Com o auxílio de uma câmera com resolução de 2.0 megapixels foram registradas várias imagens do local da coleta. As coletas e armazenamentos das amostras para análise de qualidade da água foram realizados seguindo os procedimentos adequados para garantir a integridade das amostras e a confiabilidade dos resultados. A amostra coletada foi encaminhada para análise no Laboratório de Estudos Ambientais (LEA) no Instituto de Tecnologia e Pesquisa (ITP) localizado no Campus Farolândia da Universidade Tiradentes, Aracaju/SE.

A escolha dos metais avaliados teve como base a presença de diversas fábricas na região com grande potencial de liberação desses componentes no ambiente, incluindo fábricas de metalúrgica e de fundição. Sendo assim, foram considerados relevantes a análise de Chumbo, Cádmio e Cobre. Os metais foram analisados por meio da técnica de Espectroscopia de Absorção Atômica (AAS) seguindo o Método de Determinação $3111 \mathrm{~A} \mathrm{da}$ American Water Works Association ${ }^{11}$. Essa técnica permite a determinação quantitativa dos elementos químicos presentes na amostra baseada na absorção da radiação por átomos livres no estado gasoso. Este só é possível devido a presença de uma chama que converte o aerossol da amostra em vapor

Tabela 1. Análise de metais pesados no Rio do Sal no ano de 2011.

$\begin{array}{ccc}\text { Analito } & \text { Resultados } & \text { Referência CONAMA } \\ \text { Chumbo (Pb) } & 0,01 \mathrm{mg} / \mathrm{l} & 0,033 \mathrm{mg} / \mathrm{Pb} \\ \text { Cádmio (Cd) } & 0,005 \mathrm{mg} / \mathrm{l} & 0,01 \mathrm{mg} / \mathrm{Cu} \\ \text { Cobre (Cu) } & 0,05 \mathrm{mg} / \mathrm{l} & 0,013 \mathrm{mg} / \mathrm{Cu}\end{array}$

CONAMA: Conselho Nacional do Meio Ambiente. Fonte: Autoria própria (2020). atômico, facilitando a absorção da luz de uma fonte primária ${ }^{12}$. A quantificação dos metais avaliados foi feita através do equipamento modelo Aanalyst 300 (Perkin Elmer) com software de aquisição e análise de dados AA WinLab, versão 4.1. Os resultados obtidos foram tabulados utilizando o software Microsoft Excel para posterior comparação e discussão com os dados publicados anteriormente pela Resolução CONAMA no 357.

A interpretação dos resultados foi baseada nos valores máximos para cada componente avaliado estabelecidos pela Resolução CONAMA ${ }^{11}$ no 357, de 17 de março de 2005 publicado no Diário Oficial da União - DOU No 053 págs. 58-63 que "Dispõe sobre a classificação dos corpos de água e diretrizes ambientais para o seu enquadramento, bem como estabelece as condições e padrões de lançamento de efluentes, e dá outras providências ${ }^{13}$.

\section{RESULTADOS}

Os resultados das análises toxicológicas do ano de 2011 podem ser observados na tabela 1. Os dados apresentados demonstram que o chumbo e o cádmio apresentam concentrações as quais respeitam os valores máximos ambientais estabelecidos pelo órgão ambiental de fiscalização. Por outro lado, o cobre apresentou níveis elevados em relação ao preconizado pelo mesmo órgão, o que já é um fator que põe em risco a saúde da população ribeirinha que faz uso das águas do Rio do Sal.

Além das alterações observadas pelos metais pesados, também foram analisados a contaminação ambiental devido a presença de diversos poluentes no local. No dia da coleta, foram registradas imagens para mostrar a situação em que o Rio 
do Sal se encontrava naquele período. As figuras 1 e 2 demonstram a presença de

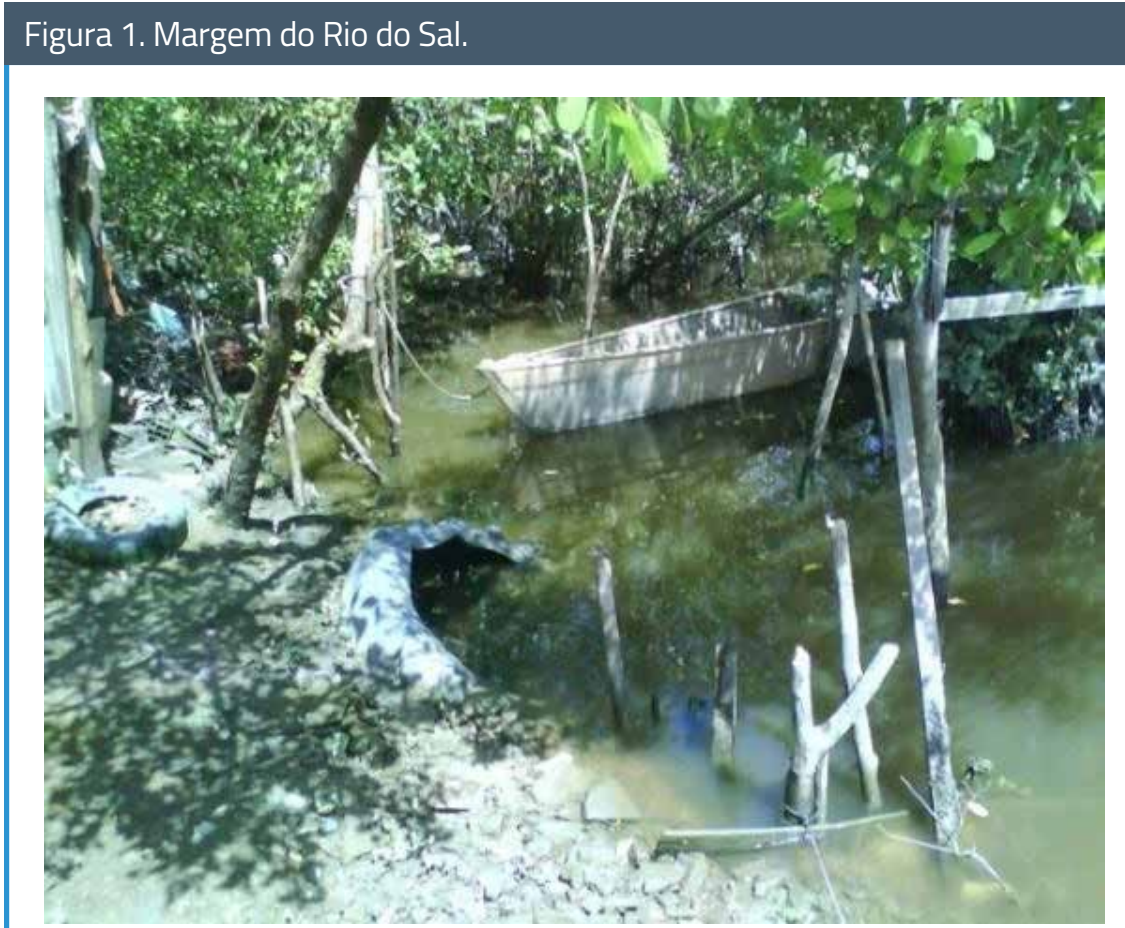

Fonte: Autoria própria (2020)

Figura 2. Presença de contaminantes no Rio do Sal.

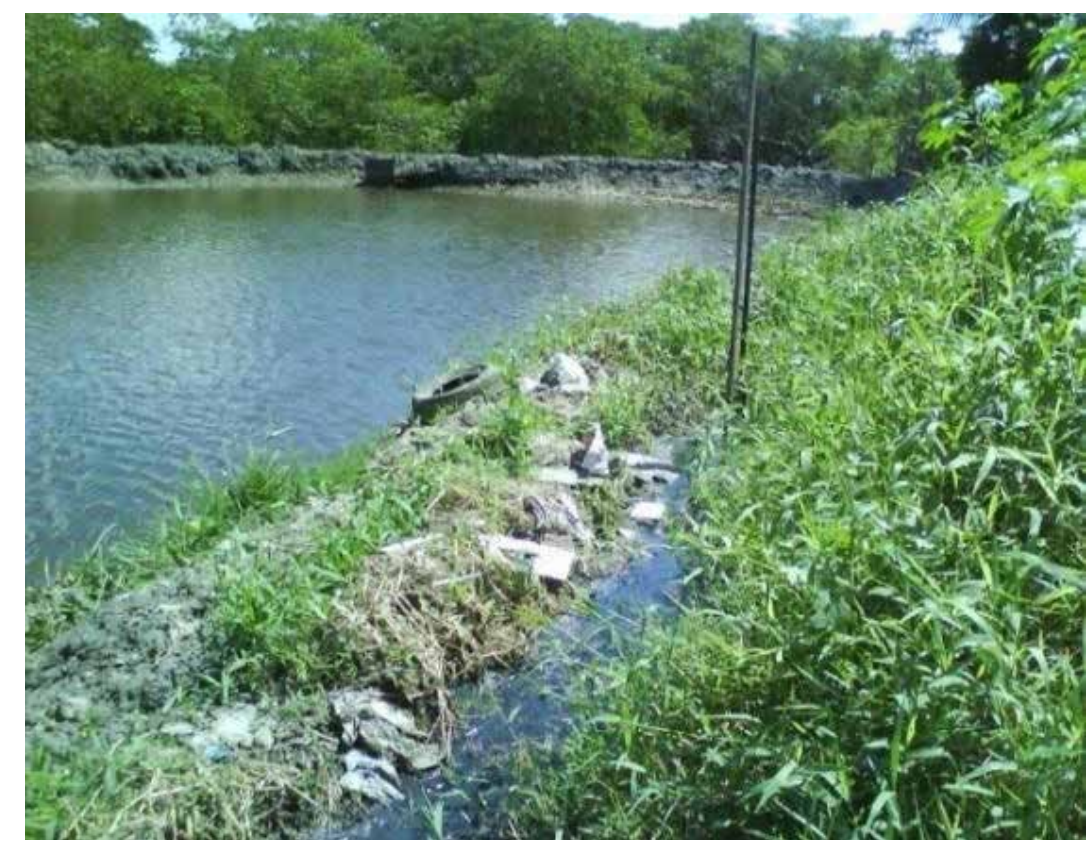

Fonte: Autoria própria (2020) variados poluentes, tais como garrafas pet, pneus, sacolas plásticas, vidros e de- jetos residenciais, onde os mesmos foram encontrados sobre as águas e às margens do rio. Esses achados contribuem para o aumento do risco à população ribeirinha além de fortalecer a necessidade de medidas sanitárias que visem o tratamento dos efluentes do Rio do Sal, bem como a sua preservação ambiental.

\section{DISCUSSÃO}

Analisando os dados gerados e relacionando-os com os teores máximos estabelecidos pela Resolução CONAMA pode-se inferir que o Chumbo e o Cádmio se encontram dentro do limite permitido. Este resultado caracteriza uma grande vantagem, uma vez que elevadas concentrações destes metais são bastante tóxicas ao organismo humano, além de causar câncer, danos neurológicos e provocar aborto em gestantes $^{14,15}$. Ao contrário do Cádmio, observa-se que o valor apresentado para o Cobre se encontra consideravelmente elevado quando comparado com os valores normais estabelecidos pelo CONAMA. Alterações como estas podem estar ligadas diretamente a concentrações destes elementos no organismo humano provenientes de exposições exógenas.

As análises de Cobre mostram concentrações aproximadamente quatro vezes mais elevadas que o teor máximo permitido. Este teor elevado pode estar relacionado à presença de indústrias existentes em torno do perímetro urbano, tais como as indústrias têxteis e de sabões. Segundo Alloway e Ayres16, a principal fonte de contaminação por este metal se dá principalmente pelos processos industriais e atividades agrícolas. O Cobre faz parte de diversos processos bioquímicos dos seres humanos, porém pode acarretar sérias complicações quando em taxas elevadas no organismo. Uma das principais consequências pela contaminação por tal elemento é a Doença de Wilson: disfunção genética onde gestantes apresentam altas concentrações desse metal acumuladas no bebê, afetando, principalmente, o fígado e o cérebro além de ocasionar distúrbios neurológicos ${ }^{17}$. 
Além do Cobre, a bacia do Rio do Sal também foi caracterizada pela presença do Cádmio, apesar de este não apresentar valores além do permitido. No entanto, é preciso ficar atento e continuar monitorando esta bacia hidrográfica na tentativa de impedir a sua concentração ao longo do rio. Sabe-se que o Cádmio é um elemento químico bastante tóxico, principalmente quando em sua forma iônica, sendo esta a forma mais comum em ambientes de água doce ou de baixa salinidade. Assim como o cobre, ele apresenta grandes chances de contaminação da população que vive às margens do Rio do Sal e são dependentes deste meio hidrográfico para a sobrevivência, além de ser responsável pela contaminação da fauna e da flora da região ${ }^{18}$.

$\mathrm{O}$ cádmio é facilmente absorvido pela natureza, principalmente pelo ambiente aquático, comprometendo todo o ecossistema. Peixes e plantas aquáticas também sofrem contaminação por este metal, o que pode ser um dos motivos pela extinção de várias espécies ${ }^{19}$. Segundo Cardoso e Cha$\sin ^{18}$, a origem principal do cádmio está relacionada com a mineração e indústria de metais. Sendo estes os principais emissores desse elemento no meio ambiente. Tal contaminação ocorre pela drenagem das minas e, também, pelas chuvas oriundas de regiões de mineração além da corrosão dos encanamentos. O contato com o cádmio pode levar a sérios problemas de saúde aos seres humanos, tais como doenças respiratórias, cardiovasculares, renais, esqueléticas e doenças hepáticas. Além dessas, ele é responsável por alterações imunológicas, doenças crônicas e câncer devido a atividade ocupacional ${ }^{18}$.

Somando-se a esses problemas, o Rio do Sal apresenta diversos outros fatores que vem afetando, diretamente, a qualidade de vida da população ribeirinha. Atualmente, o rio sofre por vários sérios problemas que estão relacionados com a falta de saneamento básico, tratamento adequado de esgotos, ocupação desordenada das suas margens, desmatamento, diversos contaminantes e lixeiras à céu aberto são os principais motivos que fazem do Rio do Sal impróprio para uso ${ }^{10}$.

Um estudo realizado por Souza ${ }^{20} \mathrm{e}$ analisado por Quinatto et al. ${ }^{21}$ avaliou a qualidade das águas do Rio do Sal através da análise de diversos parâmetros, criando um modelo empírico para o monitoramento de recursos hídricos. Os parâmetros avaliados foram Turbidez, Oxigênio dissolvido, $\mathrm{pH}$, coliformes fecais, Residual total e Demanda Biológica de Oxigênio. Avaliando os resultados obtidos, Souza concluiu que o Rio do Sal apresenta um alto grau de poluição, proveniente de lançamento de despejos domésticos e industriais, bem como de lixo urbano. Observando os resultados obtidos e relacionando - os com esta pesquisa, observa-se que o Rio do Sal não teve nenhum tratamento eficaz de descontaminação de suas águas desde 2003 até a realização do presente trabalho em 2011, o qual mostra que o mesmo ain-

Sabe-se que o

Cádmio é um

elemento químico

bastante tóxico,

principalmente

quando em sua

forma iônica,

sendo esta a forma

mais comum em

ambientes de água

doce ou de baixa

salinidade. da permanece contaminado. Dessa forma, torna-se necessário um plano de gestão de controle de suas águas no intuito de torná-las viáveis para o consumo humano e abastecimento da população dependente deste recurso ${ }^{21}$.

Lessa e Silv ${ }^{222}$ realizaram a análise dos mesmos parâmetros observados por Sou$\mathrm{za}^{18}$. No entanto, elas avaliaram a qualidade da água do Rio Sergipe no Município de Laranjeiras, localizado a Oeste do estado, ou seja, na porção inicial da bacia de Sergipe. Como resultados, observou-se que tais parâmetros se encontram dentro da normalidade, com exceção para coliformes fecais, os quais apresentaram um valor acima do normal. Observando-se que o Rio do Sal está localizado na porção terminal da bacia do Rio Sergipe, a sua contaminação por coliformes fecais pode ser proveniente do percurso que o rio faz desde a sua nascente até desaguar no Oceano Atlântico, trazendo todos esses dejetos provenientes dos outros afluentes, os quais podem ficar acumulados nas margens do rio. A atividade antrópica na região do Rio do Sal também tem contribuído para a alteração desse parâmetro, uma vez que dejetos domésticos são despejados diretamente nas águas do rio e a falta de saneamento básico é precária ${ }^{16}$.

O desequilíbrio ecológico ocasionado pela presença de metais pesados no meio ambiente contribui para a degradação ambiental, afetando a qualidade de vida dos que ali vivem ${ }^{13}$. Dessa forma, observou-se o quanto a ação antrópica pode influenciar nos problemas socioambientais além de ser o principal responsável pelas desordens do homem na natureza.

\section{CONCLUSÃO}

Os resultados acerca dos níveis de concentração de metais pesados nas águas do Rio do Sal forneceram um diagnóstico favorável quanto à presença de chumbo e cádmio. Em relação à presença do cobre os resultados apontaram valores acima do limite máximo estabelecido pelo CONAMA. Portanto, a realização de outros testes se faz necessária para melhor compreender essa 
poluição no local. Estes testes irão servir como forma de controle e acompanhamento dos níveis desses componentes no Rio do Sal, servindo como forma de avaliação de tais elementos ao longo dos anos.

Os contaminantes observados mostram que é preciso ser feita uma solici- tação de limpeza ao órgão competente da Prefeitura do Município. Além disso, é necessária a colocação de coletores de lixo em locais específicos e a realização de pesquisa-ação envolvendo habitantes das suas margens no intuito de sensibilizá-los e possibilitar vivências de atitudes que contribuirão para a sobrevivência deste rio e da qualidade de vida destes indivíduos. Para isso, recomenda-se uma efetiva gestão ambiental que foque na educação e preservação ecológica, de modo que favoreça uma maior interação entre os órgãos públicos e a sociedade.

\section{REFERÊNCIAS}

1. Estrela MA, Chaves LHG, Silva LN. Fitorremediação como solução para solos contaminados por metais pesados. Revista Ceuma Perspectivas 2018;38(1): 160-72.

2. Moura ASA, Fontes AL, Dantas MAO, Santos WDG, Santos WA. Problemas ambientais no Rio do Sal (SE) decorrente da ação antropogênica. In: Anais XVI Encontro Nacional de Geógrafos; 2010 jul 25-31; Porto Alegre, Brasil. Rio grande do Sul: Associação dos Geógrafos Brasileiros; 2010, p.1-7.

3. Frois ACF, Pereira SG. Qualidade aa Água do Rio Paranaíba na região de Patos de Minas-Mg: organoclorados e metais pesados e a sua relação com saúde pública e coletiva. Scientia Generalis 2018;1(3):54-99.

4. Jaishankar M, Tseten T, Anbalagan N, Mathew BB, Beergowda $K$. Toxicity, mechanism and health effects of some heavy metals. Interdisciplinary toxicology 2014;7(2):60-72.

5. Lima DP; Santos C; Silva RS; Yoshioka ETO; Bezerra RM; Contaminação por metais pesados em peixes e água da bacia do rio Cassiporé, Estado do Amapá, Brasil. Acta Amazonica 2015; 45(4), 405-14.

6. Moschem JC, Gonçalves PR. Impacto toxicológico de Metais Pesados: Uma análise de efeitos bioquímicos e celulares. Health and Biosciences 2020;1(2):88-100.

7. Alves JPH (Org). Rio Sergipe: Importância, vulnerabilidade e preservação. Laboratório de Química Analítica Ambiental, Universidade Federal de Sergipe (UFS). São Cristóvão, 2006.

8. Governo do Estado de Sergipe. Secretaria de Estado do Planejamento e da Ciência e Tecnologia - SEPLANTEC. Gestão participativa dos recursos hídricos. Superintendência dos Recursos Hídricos (SRH). Aracaju, SE;2002.

9. Araújo AT. Geografia de Sergipe. Aracaju; 1969.

10. Santos BM, Rodrigues F. História E Meio Ambiente: Análise da relação homem-natureza no entorno do Rio Do Sal (Aracaju-Se) [artigo na internet]. Webartigos; 2010 [acesso em 20 set 2015]. Disponivel em: http://www.webartigos.com/artigos/ historia-e-meio-ambiente-analise-da-relacao-homem-natureza-no-entorno-do-rio-do-sal-aracaju-se/30911/\#ixzz3mRyE8rh4

11. Baird RB, Eaton AD, Rice EW. Standard Methods for the examination of water and wastewater. 23rd ed. Washington, DC;2017.

12. Nascimento, PA. Caracterização do perfil químico inorgânico dos extratos de canabidiol empregados para fins terapêuticos por espectrometria em emissão óptica com plasma individualmente acoplado (ICP-OES) e desenvolvimento de métodos para a determinação de $\mathrm{As}$, Cd e Pb por espectrometria de absorção atômica por forno de grafite (Gf AAS) nesses extratos. Curitiba. Dissertação [Mestre em Química] - Universidade Federal do Paraná; 2018.

13. Brasil. Resolução N³57, de 17 de março de 2005. Publicada no Diário oficial da União 18 mar 2005; 053.

14. Moreira FR, Moreina JC, Pivetta F. Influência da Geometria da plataforma na determinação de chumbo em Zidovudina. Quim Nova 2002;25(3):379-83.

15. Grigoletto TLB, Fuzari BHC, Andrade AR, Campos MLAM, Gerlach RF, Santos JET. Fatores químicos e físicos que afetam a contaminação por chumbo e cobre em água potável: uma abordagem para o estudo de caso em química analítica. Quim. Nova 2012;35(10):1995-001.

16. Alloway BJ, Ayres DC. Chemical Principles of Environmental Pollution. 2nd ed. Blackie Academic and Professional: Glasgow; 1997.

17. Farias JC, Almeida M, Coutinho $P$, Almeida HJF, Nóbrega PV. Doença de Wilson: diagnóstico clínico e sinais das "faces do Panda" à ressonância magnética. Arq. Neuropsiquiatria 2005;63(1):176-179.

18. Cardoso LMN, Chasin AM. Ecotoxicologia do cádmio e seus compostos [série cadernos de Referência Ambiental]. Salvador: Centro de Recursos Ambientais - CRA; 2001 [acesso em 20 set 2015]. Disponivel em: http:www.intertox.com.br

19. Acosta IB, Varela Jr AS, Silva EF, Cardoso TF, Caldas JS, Jar$\operatorname{dim} \mathrm{RD}$, et al. Effects of exposure to cadmium in sperm cells of zebrafish, Danio rerio. Elsevier, Toxicology reports 2016; (3):696700.

20. Souza R, Costa J, Souza R. Construção de Modelo Empírico para o Monitoramento de Recursos Hídricos do Rio Do Sal/Sergipe. Brazilian Journal of Environmental Sciences 2007;(08):16-28.

21. Quinatto J, Zambelli NLN, Souza DH, Neto SLR, Cardoso JT, Skoronski E. Using the pollutant load concept to assess water quality in an urban river: the case of Carahá River (Lages, Brazil). Rev Ambient Água 2019;14(1):e2252.

22. Lessa MMD, Silva AAG. Avaliação da Qualidade da Água do Rio Sergipe no Município de Laranjeiras, Sergipe - Brasil [Apresentação no VII Encontro de Recursos Hídricos em Sergipe; 2014 mar 19 e 20; Aracaju, Brasil]. 